\title{
Precipitation-dependent source-sink dynamics in a spatially-structured population of an outbreaking caterpillar
}

\author{
Patrick Grof-Tisza (i) - Adam Pepi • Marcel Holyoak • Richard Karban
}

Received: 18 August 2018/ Accepted: 4 March 2019/Published online: 28 March 2019

(C) The Author(s) 2019

\begin{abstract}
Context Patch-based population models predominately focus on factors that affect regional processes namely, patch size and connectivity, as the primary drivers explaining patch occupancy. This trend persists despite the recognition that patch quality can strongly influence population demography at the local scale. The quality of patches is often temporally variable and influenced by abiotic conditions. However, few studies have explicitly investigated how climatic variables influence the spatial and temporal dynamics of spatially-structured populations either directly or indirectly through changes in patch quality. Objectives Using a 10-year census of a spatiallystructured population of an outbreaking caterpillar, we
\end{abstract}

Electronic supplementary material The online version of this article (https://doi.org/10.1007/s10980-019-00793-z) contains supplementary material, which is available to authorized users.

P. Grof-Tisza · A. Pepi · R. Karban

Department of Entomology and Nematology, University

of California, 1 Shields Ave, Davis, CA 95616, USA

P. Grof-Tisza ( $\square)$

Department of Biological and Environmental Sciences, University of Eastern Finland, Kuopio 70200, Finland e-mail: p.groftisza@gmail.com

\section{Holyoak}

Department of Environmental Science and Policy, University of California, 1 Shields Ave, Davis, CA 95616, USA determined the relative importance of patch quality (determined demographically), connectivity, precipitation, and their interactive effects on patch abundance, occupancy, colonization, and extinction.

Methods We generated a series of statistical models and performed comparisons using Akaike's information criterion. We subsequently used likelihood ratio tests to determine the influence of each parameter on model fit.

Results Patch quality and precipitation were the strongest predictors of the observed dynamics. We found that the dynamics of the spatially-structured population of Arctia virginalis were strongly influenced by precipitation: all patches had a higher probability of occupancy, contained higher abundances of caterpillars, and experienced fewer extinctions following wet winters compared to years following droughts.

Conclusion These findings suggest that precipitation may act to influence the strength of heterogeneity of patch quality. This work demonstrates that patchbased models that do not include local and climatic factors may produce poor predictions under future climatic regimes.

Keywords Area-isolation paradigm - Climate change $\cdot$ Hilltopping $\cdot$ Metapopulation $\cdot$ Patch quality 


\section{Introduction}

Empirical studies spanning several taxa have validated theoretical patch-based models demonstrating that patch size and isolation explained extinction-colonization dynamics (Thomas and Harrison 1992; Hanski and Thomas 1994; Rabasa et al. 2008); the probability of stochastic extinctions was found to be negatively correlated with patch size and the probability of (re)colonization was positively correlated with increased connectivity (or inversely, isolation; Hanski 1994). A seminal paper by Moilanen and Hanski (1998) concluded that the inclusion of patchlevel environmental variables into metapopulation models did not increase explanatory power. Consequently, over the next two decades, most studies investigating the spatial dynamics of spatially-structured populations focused on patch geometry and ignored patch quality (but see Thomas et al. 2001; Fleishman et al. 2002). A meta-analysis, however, found that patch area and isolation accounted for only $25 \%$ of the variation in patch occupancy (Prugh et al. 2008). Indeed, several studies demonstrated that the observed spatial dynamics were not consistent with the area-and-isolation paradigm (Hanski 1998), reporting that factors other than patch geometry, namely proxies for patch quality, were the strongest predictors (Schooley and Branch 2009; Franzén and Nilsson 2010; Robles and Ciuad 2012). Learning from the resolution of the decade-long bottom-up, top-down debate (Hunter and Price 1992), the field is shifting from determining if local (e.g., quality) or regional (e.g., patch geometry) factors are more important to determining the relative importance of both and under what conditions they predominate.

One issue with including a quality metric in metapopulation and other similar patch-based models hinges on the difficulty of assessing habitat patch quality. Indeed, simply defining quality has proved challenging (see Mortelliti et al. 2010 for an overview of quality definitions). While debated, the definition proposed by Hall et al. (1997) is widely accepted: "habitat quality is the ability of the environment to provide conditions appropriate for individual and population persistence." Abundances and density are often used as an indicator of patch quality. However, in systems characterized by high patch heterogeneity, only a small fraction of a population may occur in patches with sufficient quality to support successful breeding (Pulliam 1988). Moreover, relying on periodic censuses does not account for dispersal between patches, a hallmark of spatially-structured populations; changes in abundance may erroneously be attributed to patch-dependent mortality or birth rates and not individual movement. Other common proxies of patch quality include physical attributes such as area (e.g., Anzures-Dadda and Manson 2007) or limited resources thought to be important for focal species such as trophic resources (e.g., Fleishman et al. 2002; Franzén and Nilsson 2010) and breeding habitat (e.g., Robles and Ciuad 2012). Less common proxies are top-down factors. Often considered separately from patch quality, the presence of predators can influence the establishment or persistence of species in a patch (Shurin 2001; Kneitel and Miller 2003; Grainger et al. 2017) or deter colonization processes (i.e., habitat selection and immigration; Resetarits et al. 2018). The utility of using these proxies is contingent upon the strength of the relationship between the quantifiable dependent variable and actual patch quality. However, experimentally establishing a quantitative relationship between proxies and survival or reproductive success, while controlling for individual movement, is rare (Diffendorfer 1998).

While the incorporation of local, patch-level factors is increasing, few studies have explicitly modeled how changes in weather patterns influenced the spatial and temporal dynamics of spatially-structured populations (but see Pardikes et al. 2015; Tack et al. 2015; Kahilainen et al. 2018). Yet changes in precipitation and temperature can either directly (Huey and Kingsolver 1989; Karban et al. 2015) or indirectly influence local and regional processes through loss of habitat (Johnson 2004) or changes in bottom-up (Boughton 1999) and top-down (Pepi et al. 2018) forces driving patch-quality. One explanation for the paucity of studies incorporating climatic variables is that early metapopulation models pooled occupancy data over multiple years to account for stochastic environmental fluctuations as opposed to explicitly quantifying their effects (Hanski et al. 1996; Moilanen 1999). Scientists are in broad agreement that climate is changing (IPCC 2014; Pachauri and Meyer 2014), and climate models predict a more variable future with increased frequency of extreme weather events leading to droughts and floods (Coumou and Rahmstorf 2012). Elucidating the mechanisms underlying the link between 
variation in weather and processes at the local and regional scales will increase our understanding of how a changing climate will affect the persistence of spatially-structured populations.

Our research investigated the dynamics of a spatially-structured population of a hilltopping tiger moth, Arctia virginalis. This research was motivated by our previous work analyzing a 5-year caterpillar census (Karban et al. 2012) and subsequent caging studies in the field (Karban et al. 2013, 2017); through this work, we found that within-patch demography was dependent on patch quality. The contributions of patch geometry and seasonal weather to the dynamics of A. virginalis have yet to be assessed. Using an additional 5 years of census data (10 years total), we evaluated the relative importance of local, regional, and climatic drivers and their interactive effects on several common metapopulation parameters. Specifically, we quantified the relative effects of patch quality, patch connectivity, total annual precipitation and their interactions on common metapopulation parameters we measured as responses, including patch-level caterpillar abundance, and the probabilities of patch occupancy, colonization, and extinction. Previous work in this system demonstrated that precipitation positively correlated with caterpillar abundance, potentially through the displacement of predatory ants (Karban et al. 2017). Because of this a prori knowledge and our interest in interactive effects, but with limited data, we focused solely on precipitation as the climatic driver. In light of previous findings, we hypothesized that (1) patch quality is the primary factor driving the dynamics of $A$. virginalis, but the magnitude of its effect is dependent on precipitation and (2) a positive relationship between connectivity and all responses except for extinction, which should have a negative relationship with this parameter. Our measure of connectivity accounts for lekking behavior on local summits (i.e., hilltopping). This metric better reflects constrained dispersal exhibited by hilltopping species as compared to conventional connectivity metrics that assume that dispersal occurs randomly among patches. Consequently, patches closest to hilltops with large mating aggregations (i.e., high connectivity) should exhibit higher occupancy with more caterpillars and colonization events but fewer extinctions compared to those patches with lower connectivity (see Online Resource 1 for map showing connectivity).

\section{Methods}

The study system

Surveys and experiments were conducted within the Bodega Marine Reserve (BMR), Sonoma County, California $\left(38.3184^{\circ} \mathrm{N}, 123.0718^{\circ} \mathrm{W}\right)$. Our study site experiences hot, dry summers and cool, wet winters, typical of a Mediterranean climate. Arctia virginalis [Lepidoptera; Erebidae] is a patchily distributed, dayflying moth in the western United States (Powell and Opler 2009). Caterpillars leave larval patches and pupate in late spring (April-June). Adults engage in hilltopping behavior during June-August (Grof-Tisza et al. 2016). Similar to lek mating systems, hilltopping is a common mate-locating strategy used by insects: individuals aggregate on summits and ridges, thereby increasing their likelihood of finding a mate (Shields 1967; Alcock 1987). Only a few hilltopping sites are used within BMR, with most individuals (>70\%) aggregating on the highest elevation summits (GrofTisza et al. 2017; Online Resource 1). After mating, females disperse from summits and search for suitable habitat patches to oviposit. Consequently, dispersal is constrained by these mating aggregations and does not originate from larval patches as commonly assumed in most patch-based models.

Larval patches are comprised of bush lupine (Lupinus arboreus) stands, the primary host plant at our study site. L. arboreus patches are common within the dominant coastal prairie habitat and on the periphery of low-lying, fresh water marsh habitat. A 5-year caterpillar census showed that this system conformed to predictions consistent with source-sink dynamics; caterpillar abundances were consistently higher and finite growth rates were greater than one in marsh habitat patches compared to coastal prairie patches, where caterpillar abundances were often low and finite growth rates were less than one, such that some patches went locally extinct in some years (Karban et al. 2012). Experimental work demonstrated that both bottom-up (BU) and top-down (TD) forces were drivers of this pattern; survival was higher for early instar caterpillars in marsh than prairie habitat when reared on $L$. arboreus plants using fine mesh cages that excluded predatory ants (BU; in preparation) and predation of caterpillars by ants was higher in prairie than marsh habitat (TD; Karban et al. 2013). Following Hall et al. (1997), we used these 
demographic studies to assign values of patch quality. Patches within marsh and prairie habitat were categorized as high- and low-quality, respectively. As previously mentioned, quantifying patch-associated mortality to assess patch quality is a more direct measure than relying on census data or the abundance of trophic resources.

\section{Census}

An ongoing census program for $P$. virginals has surveyed 13 larval patches within BMR since 2007 described elsewhere (Karban et al. 2012; Online Resource 1). Briefly, we counted the number of caterpillars observed on haphazardly selected lupine plants $(\mathrm{n}=10,2007-2011 ; \mathrm{n}=15,2011-2016)$ of similar size in March of each year and we tallied the total number caterpillars observed per patch. For this study, we compiled 10 years (2007-2016) of patchlevel annual caterpillar census data, including caterpillar counts, occupancy, extinction (i.e., no caterpillars observed in a previously occupied patch; 2008-2016) and colonization (observing at least 1 caterpillar in a site that was deemed extinct during the previous year; 2008-2016). In addition to summarizing our census data across all patches for all years, we provide a summary table grouped by patch quality (Table 1).

\section{Patch structure}

Using a high-resolution satellite image of BMR (Google Earth Pro; image date, 6 June 2017), we obtained spatial coordinates of the centroids of larval patches ( $\mathrm{n}=13$; Online Resource 1$)$ and previously identified adult mating aggregation summits $(n=5$; Grof-Tisza et al. 2017). Distance from the centroid of each larval patch to each aggregation summit was obtained using the 'Imap' package in R (R Development Core Team 2011). Centroids, as opposed to patch edges, were used because the perimeter of patches varied annually depending on death and recruitment of L. arboreus plants. The area of patches was estimated for the extant patches in 2017 using the satellite image described above. Because we only had 1 year of patch area data (1 year beyond our 10-year census; 2007-2016) and it fluctuated annually, we did not consider patch area in our analysis but report patch area for 2017 in an appendix (Online Resource 2).
We used distance between each larval patch and aggregation summit centroid to calculate a connectivity index. Unlike most connectivity indices that assume random dispersal between patches, our connectivity metric incorporates mating behavior; for hilltopping insects, females use elevational cues to navigate to summits, mate, and then descend to locate suitable oviposition sites. Consequently, dispersal is a directed (i.e., non-random) process influenced by topography (Pe'er et al. 2004, Pe'er et al. 2013; Painter 2014; Grof-Tisza et al. 2017). Our model assumes a fragmented landscape with discrete adult aggregation sites (summits) and larval patches,

$C_{i}=\sum_{j \neq i}^{n} e^{-d_{i j}} / \alpha H_{j}$

where $C_{i}$ is the connectivity of patch $i, d$ is the Euclidean distance between any patch $i$ and any adult aggregation summit $j, \alpha$ is the mean dispersal distance of $A$. virginalis moths, and $H$ is the density of female moths at hilltop $j$ determined in a previous study (Grof-Tisza et al. 2017). $H$ in our model is analogous to the area of source patches in conventional connectivity models (Hanski and Thomas 1994), which is thought to be proportional to population size and accordingly, the number of dispersing propagules. Though we only estimated mating aggregation size in 1 year, surveys over the 10 -year period indicated that the same summits are used annually at similar relative frequencies (Grof-Tisza et al. 2016, 2017). We used an $\alpha$ of $300 \mathrm{~m}$, derived from the average of the maximum flight distance recorded during a mark-recapture study for male $(340 \mathrm{~m})$ and female $(260 \mathrm{~m})$ moths, respectively (Grof-Tisza et al. 2017). We also tested an $\alpha$ of $1000 \mathrm{~m}$, a value commonly used for connectivity analyses when the dispersal ability of a focal butterfly is unknown. The relative importance of parameters (i.e., connectivity, patch quality, precipitation) did not change under this scenario of low dispersal limitation (data not shown). The connectivity index can be interpreted as the sum of the predicted movement by mated female moths from aggregation summits to a focal larval patch weighted by moth density, assuming that the frequency of movement decreases exponentially with distance and dispersal capacity. 


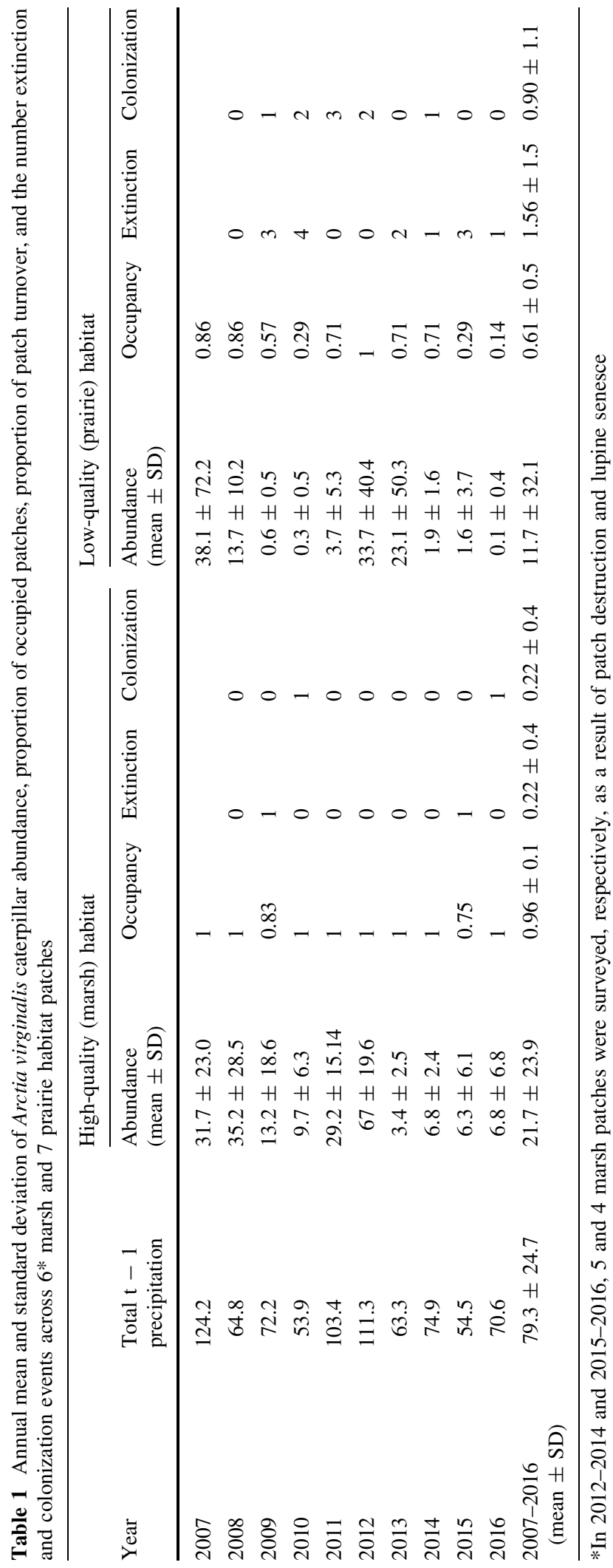


Statistical modeling

We constructed generalized linear mixed models representing all possible combinations of predictors and two-way interactions to test the influence of connectivity, patch quality, precipitation and their interactive effects on four response variables: caterpillar abundance and the probabilities of occupancy, colonization, and extinction (Table 2). Because previous work demonstrated that precipitation in year $\mathrm{t}-1$ was a good predictor of $A$. virginalis caterpillar abundance in year t (Karban and de Valpine 2010; Karban et al. 2017), we used total annual precipitation of the previous water year (i.e., hydrological year; 1 October to 31 September of $t-1$ ) in our analyses. We fit models in $\mathrm{R}$ using the glmmADMB package (Fournier et al. 2012). Patch abundance was modeled using a negative binomial error distribution with a log-link function to account for overdispersion in our count data (Ver Hoef and Boveng 2007). For all other models, we used a binomial error distribution with a logit-link function. We included "patch" as a random effect to account for repeated measures covariance structure.

We performed model comparisons using Akaike's information criterion corrected for sample size (AICc) and ranked models using delta-AICc values $\left(\Delta_{\mathrm{i}}=\right.$ $\left.\mathrm{AICc}_{\mathrm{i}}-\mathrm{AICc}_{\mathrm{min}}\right)$. We report parameter estimates for both the best performing model $\left(\mathrm{AICc}_{\mathrm{min}}\right.$ ) and results from likelihood ratio tests, which were used to determine the influence of each parameter on model fit. Parameters were estimated by the maximum likelihood method (using the Laplace approximation for GLMMs; Bolker et al. 2009). Prior to analysis, we
Table 2 Parameters (q, patch quality; c, connectivity; $\mathrm{p}, \mathrm{t}-1$ precipitation) and model comparisons (Akaike statistics corrected for sample size) for response variables (Patch-level caterpillar abundance and probabilities of patch occupancy, colonization, and extinction) for a spatially-structured population of A. virginalis, in a 10 -year study

\begin{tabular}{|c|c|c|c|c|c|c|c|c|c|}
\hline \multirow[b]{2}{*}{ Model no. } & \multirow[b]{2}{*}{ Parameters } & \multicolumn{2}{|c|}{ Abundance } & \multicolumn{2}{|c|}{ Occupancy } & \multicolumn{2}{|c|}{ Colonization } & \multicolumn{2}{|c|}{ Extinction } \\
\hline & & $\Delta \mathrm{AIC}_{\mathrm{c}}$ & $\begin{array}{l}\text { AICc } \\
\text { weight }\end{array}$ & $\Delta \mathrm{AIC}_{\mathrm{c}}$ & $\begin{array}{l}\text { AICc } \\
\text { weight }\end{array}$ & $\Delta \mathrm{AIC}_{\mathrm{c}}$ & $\begin{array}{l}\text { AICc } \\
\text { weight }\end{array}$ & $\Delta \mathrm{AIC}_{\mathrm{c}}$ & $\begin{array}{l}\text { AICc } \\
\text { weight }\end{array}$ \\
\hline 1 & $\sim \mathrm{q} \times \mathrm{c}+\mathrm{q} \times \mathrm{p}+\mathrm{p} \times \mathrm{c}$ & 2.7 & 0.04 & 6.2 & 0.01 & 1.6 & 0.10 & 5.3 & 0.02 \\
\hline 2 & $\sim \mathrm{q} \times \mathrm{c}+\mathrm{q} \times \mathrm{p}$ & 2.4 & 0.05 & 4.4 & 0.03 & 4.9 & 0.02 & 5.9 & 0.02 \\
\hline 3 & $\sim \mathrm{q} \times \mathrm{c}+\mathrm{p} \times \mathrm{c}$ & 0.5 & 0.12 & 4 & 0.04 & 5.8 & 0.01 & 3.8 & 0.05 \\
\hline 4 & $\sim \mathrm{q} \times \mathrm{p}+\mathrm{p} \times \mathrm{c}$ & 2.2 & 0.05 & 3.9 & 0.04 & $\mathbf{0}$ & 0.22 & 3.2 & 0.07 \\
\hline 5 & $\sim \mathrm{q} \times \mathrm{c}+\mathrm{p}$ & 0.1 & 0.15 & 2.2 & 0.09 & 6.1 & 0.01 & 3.8 & 0.05 \\
\hline 6 & $\sim \mathrm{q} \times \mathrm{p}+\mathrm{c}$ & 2.1 & 0.06 & 2.2 & 0.09 & 2.8 & 0.06 & 3.9 & 0.05 \\
\hline 7 & $\sim \mathrm{p} \times \mathrm{c}+\mathrm{q}$ & 0.1 & 0.16 & 1.8 & 0.11 & 3.5 & 0.04 & 1.7 & 0.14 \\
\hline 8 & $\sim \mathrm{q} \times \mathrm{c}$ & 18.7 & $<0.001$ & 12.2 & $<0.001$ & 6.2 & 0.01 & 12.9 & $<0.001$ \\
\hline 9 & $\sim \mathrm{q} \times \mathrm{p}$ & 2.6 & 0.04 & 2.4 & 0.08 & 0.6 & 0.16 & 2.1 & 0.11 \\
\hline 10 & $\sim \mathrm{p} \times \mathrm{c}$ & 5.1 & 0.01 & 15.4 & $<0.001$ & 4.4 & 0.02 & 6.5 & 0.01 \\
\hline 11 & $\sim \mathrm{q}+\mathrm{c}+\mathrm{p}$ & $\mathbf{0}$ & 0.16 & $\mathbf{0}$ & 0.27 & 4 & 0.03 & 1.8 & 0.13 \\
\hline 12 & $\sim \mathrm{q}+\mathrm{c}$ & 19.6 & $<0.001$ & 10 & 0.00 & 4.2 & 0.03 & 10.9 & 0.00 \\
\hline 13 & $\sim \mathrm{c}+\mathrm{p}$ & 5 & 0.01 & 13.4 & $<0.001$ & 4.6 & 0.02 & 6.3 & 0.01 \\
\hline 14 & $\sim q+p$ & 0.7 & 0.12 & 0.3 & 0.23 & 1.9 & 0.08 & $\mathbf{0}$ & 0.32 \\
\hline 15 & $\sim \mathrm{q}$ & 24 & $<0.001$ & 10.4 & 0.00 & 2.1 & 0.08 & 9.1 & 0.00 \\
\hline 16 & $\sim \mathrm{c}$ & 27.5 & $<0.001$ & 23.9 & $<0.001$ & 4.7 & 0.02 & 15.1 & $<0.001$ \\
\hline 17 & $\sim \mathrm{p}$ & 3.1 & 0.03 & 11.3 & $<0.001$ & 3.2 & 0.04 & 6.3 & 0.01 \\
\hline 18 & $\sim$ intercept & 26.4 & $<0.001$ & 21.9 & $<0.001$ & 3.3 & 0.04 & 15 & $<0.001$ \\
\hline
\end{tabular}

An $\alpha=0.3 \mathrm{~km}$ was used to calculate connectivity. All models included "patch" as a random effect to account for a repeated measures experimental design. Models with strong support $\left(\Delta \mathrm{AIC}_{\mathrm{c}}<2\right)$ are shown in boldface. 'Abundance' was modeled using a negative binomial error distribution; the other response variables were molded using a binomial error distribution. Akaike weight (AICc weight) is the probability that a given model is best among all candidate models, given the data 
standardized all predictor variables by subtracting the mean and dividing by two times the standard deviation (Gelman 2008). This standardization allowed for the direct comparison of parameter effects, including those between continuous and categorical variables. We assessed multicollinearity between predictor variables by measuring the variance inflation factor (VIF), which was low in all cases (VIF $<1$ ). Figures used parameter estimates from the best performing model for each response variable and included only fixed effects due to issues with estimating confidence intervals of generalized linear mixed models with random effects (Bates et al. 2015).

\section{Results}

Census

Over the 10-year sampling period, caterpillar abundance varied from 0 to 200 caterpillars per patch (mean $\pm \mathrm{SD}, 16.0 \pm 29.2$ ). The proportion of patches that were occupied ranged from 0.14 to 1 per year (mean $\pm \mathrm{SD}, 0.79 \pm 0.27$ ). The number of patch colonization and extinction events was 11 and 16, respectively. Differences in caterpillar abundance, proportion of occupied patches, and the number of colonization and extinction events across high-and low-quality patches are illustrated in Table 1 (but see "Results"; "Statistical modeling").

\section{Patch structure}

Two patches were dropped from the annual census due to the bulldozing of 'Dorm Marsh' in 2012 by reserve managers and the natural senescence of $L$. arboreus bushes comprising 'Bay Marsh' in 2015. The following description of patch structure includes all patches (i.e., years 2007-2011; see Online Resource 3 for descriptive statistics during all census years). The mean distance $( \pm \mathrm{SD})$ between aggregation summits and larval patches was $906.7 \pm 462.2 \mathrm{~m}$. These distances were used to calculate a dimensionless connectivity index. The connectivity index values ranged from 4.9 to 75.9 , with an aggregate mean \pm SD of $25.9 \pm 18.0$; connectivity did not differ between low-quality (mean $\pm \mathrm{SD}, 31.0 \pm 20.3$ ) and high-quality (mean $\pm \mathrm{SD}, 19.1 \pm 11.4$ ) patches $(\mathrm{t}=1.41, \mathrm{df}=9.73, \mathrm{P}=0.19)$.
Statistical modeling

The best fitting model ( $\mathrm{AICc}_{\min }$ ) explaining patchlevel caterpillar abundance included patch quality, precipitation, and connectivity (Tables 2,3 ); caterpillar abundance was nearly $2 \times$ higher in high-quality than low-quality patches (Table 1; Fig. 1). A $1 \mathrm{~cm}$ increase in rain in year $\mathrm{t}-1$ corresponded to an increase of 3.7 caterpillars. We found a positive relationship between patch connectivity and caterpillar abundance, but this connectivity parameter did not improve model fit according to a likelihood ratio test (Table 3; Fig. 1).

The probability of patch occupancy was best explained by patch quality, precipitation, and connectivity (Tables 2,3 ). The proportion of occupied patches was $1.6 \times$ higher in high-quality than low-quality patches (Table 1). The overall effect size for connectivity was less than half of that for patch quality. As we expected, increased connectivity was positively correlated with occupancy; this was especially true for lowquality patches (Fig. 2). Despite some model support, the connectivity parameter, neither alone nor in an interaction with path quality, improved model fit (Tables 2, 3).

The best fitting model predicting the probability of colonization included two interaction terms: precipitation $\times$ connectivity and precipitation $\times$ quality, but only the latter term moderately improved model fit (Tables 2, 3); precipitation positively correlated with colonization, but for only low-quality patches (Fig. 3). Total colonization events were $4.5 \times$ more frequent in low-quality than high-quality patches (Table 1). This is likely a function of colonization potential; low-quality patches were more often extinct and consequently had more opportunities to be recolonized than high-quality patches during summers following wet years.

The probability of patch extinction was best explained by patch quality and precipitation, with the effect size for precipitation being nearly $2 \times$ larger than for patch quality (Table 3 ). Total extinction events were over $7 \times$ more frequent in low-quality than high-quality patches and were more likely to occur following drought years (Table 1; Fig. 4).

For all response variables tested, we found substantial support $(\Delta$-AICc $<2)$ for additional models, especially those containing interactions with connectivity (Table 2, Online Resource 4). For example, we 
Table 3 Parameter estimates and standard error for the most parsimonious models $\left(\mathrm{AICc}_{\text {min }}\right)$ determined through AICc model comparison for the four dependent variables of interest; for these best performing models, we used backwards step deletion (1 degree of freedom) from the full model (i.e., maximum number of parameters in $\mathrm{AICc}_{\text {min }}$ ) and likelihood ratio tests (LRT) to determine the contribution of each parameter to overall model fit

\begin{tabular}{lcccrr}
\hline Response variable and fixed effect & Standardized effect size & SE & $X^{2}$ df & LRT & P value \\
\hline Caterpillar abundance & & & & & \\
$\quad$ Quality & 1.47 & 0.50 & 1 & 4.62 & 0.03 \\
Connectivity & 0.86 & 0.49 & 1 & 2.86 & 0.09 \\
Precipitation & 1.33 & 0.27 & 1 & 25.47 & $<0.001$ \\
Probability of patch occupancy & & & & & \\
Quality & 3.36 & 0.88 & 1 & 13.57 & $<0.001$ \\
Connectivity & 0.98 & 0.60 & 1 & 2.5 & 0.11 \\
Precipitation & 2.04 & 0.69 & 1 & 12.2 & $<0.001$ \\
Probability of patch colonization & & & & & \\
Quality & -2.01 & 1.50 & 1 & 3.30 & 0.07 \\
Connectivity & -0.14 & 0.82 & 1 & 0.08 & 0.78 \\
Precipitation & 2.33 & 0.98 & 1 & 2.33 & 0.13 \\
Quality $\times$ precipitation & -5.94 & 3.47 & 1 & 5.79 & 0.06 \\
Connectivity $\times$ precipitation & -3.73 & 1.99 & 1 & 2.75 & 0.10 \\
Probability of patch extinction & & & & & \\
Quality & -1.99 & 0.81 & 1 & 7.96 & 0.01 \\
Precipitation & -3.60 & 1.42 & 1 & 11.27 & $<0.001$ \\
\hline & & & &
\end{tabular}

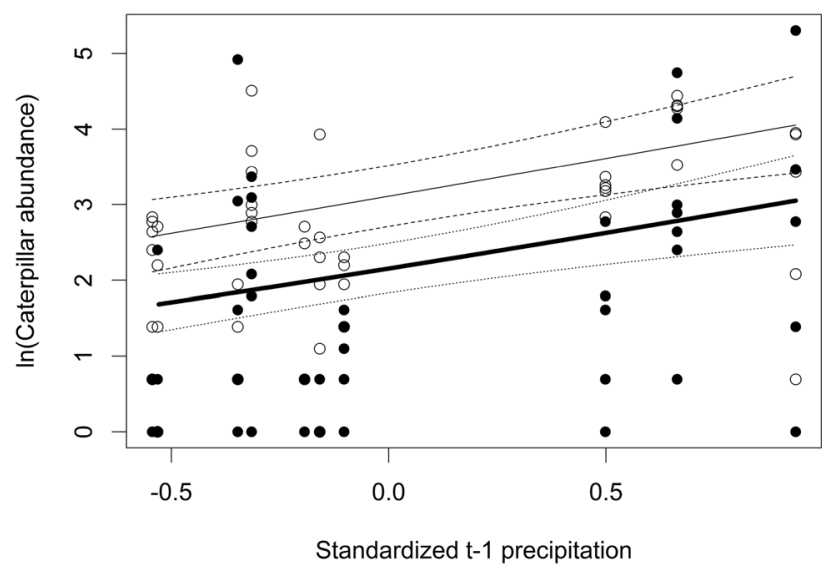

Fig. 1 The relationship between log abundance of caterpillars and standardized precipitation (left panel) and standardized connectivity (right panel). Solid center lines represent best fit from statistical models and dashed outer lines represent the $95 \%$

found support $(\Delta$-AICc $=0.1)$ for a model containing a precipitation $\times$ connectivity parameter for predicting the probability of occupancy (Online Resource 5); there was a strong positive relationship between precipitation and the probability of occupancy but only for less connected (i.e., more isolated) patches. However, most of the parameters in these models did not significantly increase model fit according to likelihood ratio tests. Because we only had 10 years

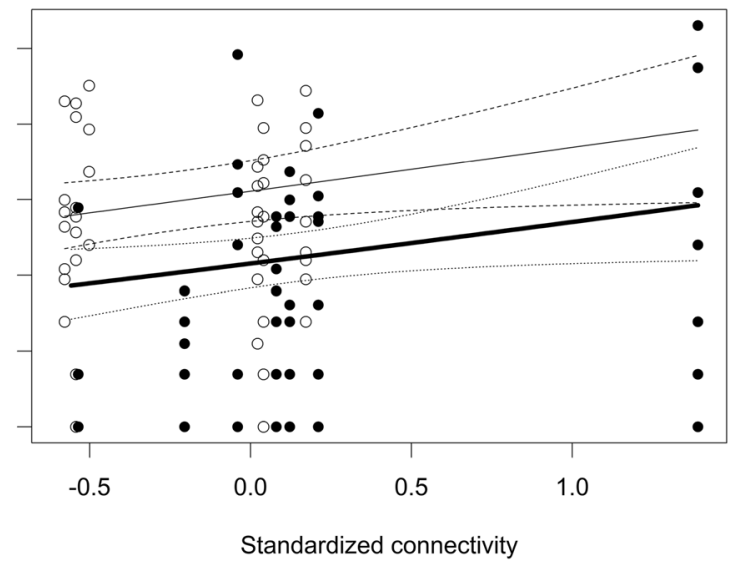

confidence interval. Thin and thick center lines represent highand low-quality patches, respectively. White and black circles represent the raw data for high-and low-quality sites, respectively

of precipitation data, we had low power to test interactive effects.

\section{Discussion}

In agreement with other studies (Thomas et al. 2001; Fleishman et al. 2002; Schooley and Branch 2009; Franzén and Nilsson 2010; Robles and Ciuad 2012), our results support the inclusion of local factors in 


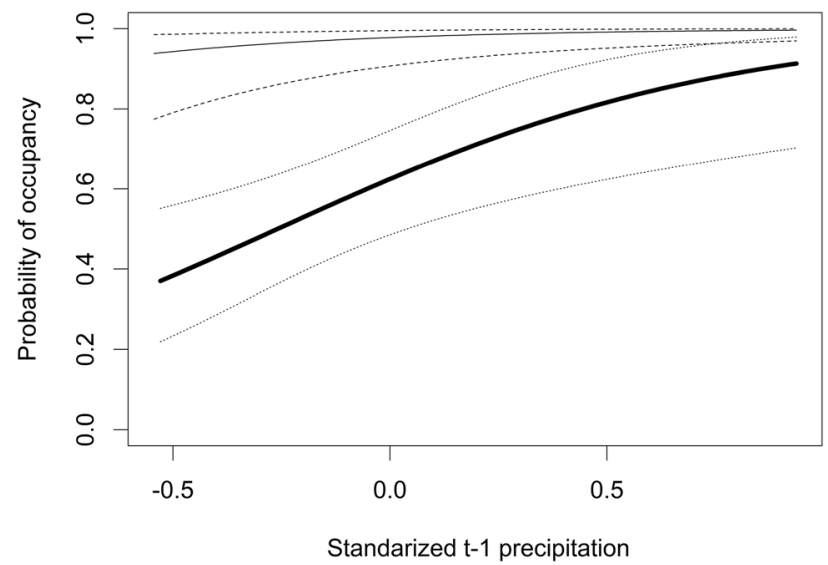

Fig. 2 The relationship between the probability of patch occupancy and standardized precipitation (left panel) and standardized connectivity (right panel). Solid center lines

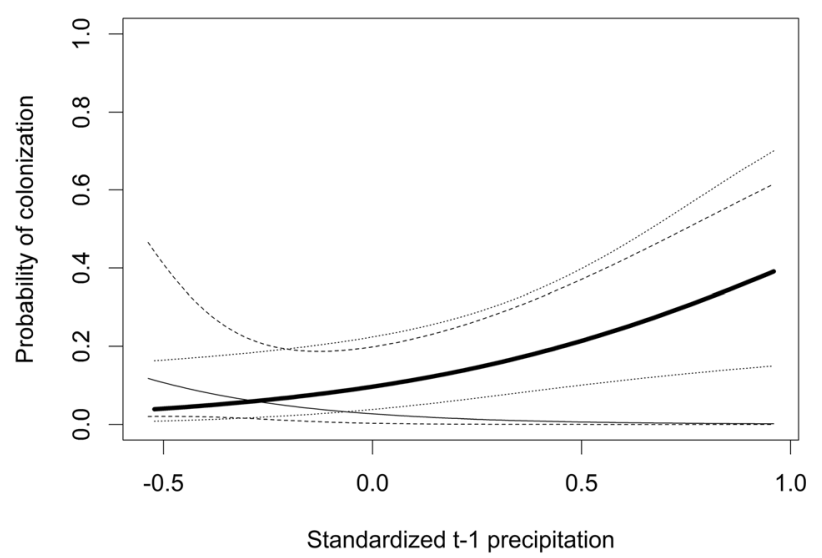

Fig. 3 The relationship between the probability of patch colonization and standardized precipitation. Solid center lines represent best fit from statistical models and dashed outer lines represent the $95 \%$ confidence interval. Thin and thick

patch-based population models; patch quality was a strong driver of the observed dynamics of $A$. virginalis caterpillars. Over the ten-year study, high-quality patches were generally occupied with higher caterpillar abundances and experienced fewer local extinctions compared to low-quality patches, regardless of connectivity. These results were largely dependent on precipitation; the probability of occupancy and extinction were indistinguishable in years following wet winters but differed following droughts, with droughts being the most important factor predicting patch extinctions. Additionally, we found an interaction between precipitation and patch quality explaining the probability of patch colonization. In light of our earlier

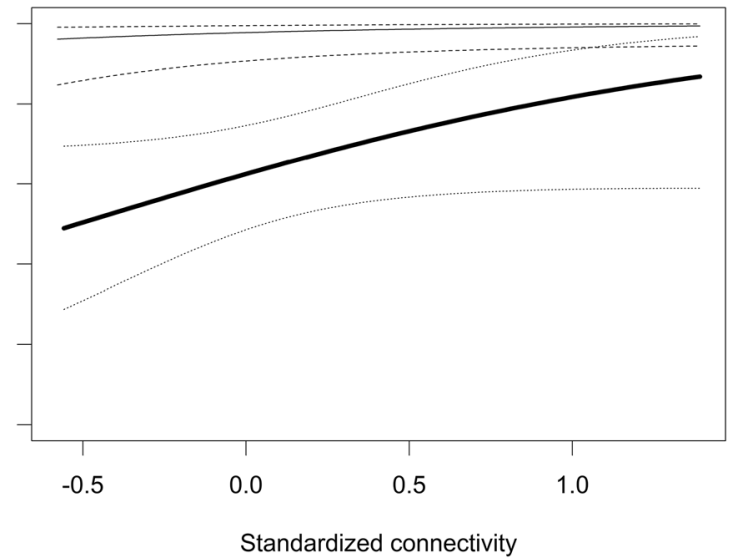

represent best fit from statistical models and dashed outer lines represent the $95 \%$ confidence interval. Thin and thick center lines represent high- and low-quality patches, respectively

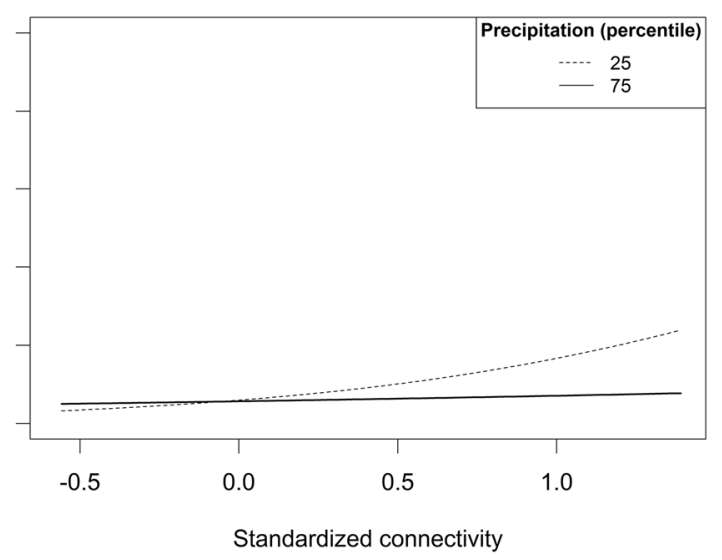

center lines represent high- and low-quality patches, respectively (Left panel). The relationship between the probability of patch colonization and the interaction of standardized connectivity and precipitation (Right panel)

work, these findings suggest that increased precipitation may reduce heterogeneity of patch quality, potentially through the displacement or numerical reduction of predatory, ground-dwelling ants that prefer dry soil (Karban et al. 2017). Alternatively, or in addition, rainy winters may decrease patch-to-patch variation in bottom-up processes the following season. However, because the demographic studies which we used to assign patch quality were only conducted in a subset of years and not in each year of this study, we cannot make strong inferences regarding the influence of precipitation on patch quality. This work demonstrates that in addition to underlying heterogeneity of patch quality, climatic variables may drive source- 


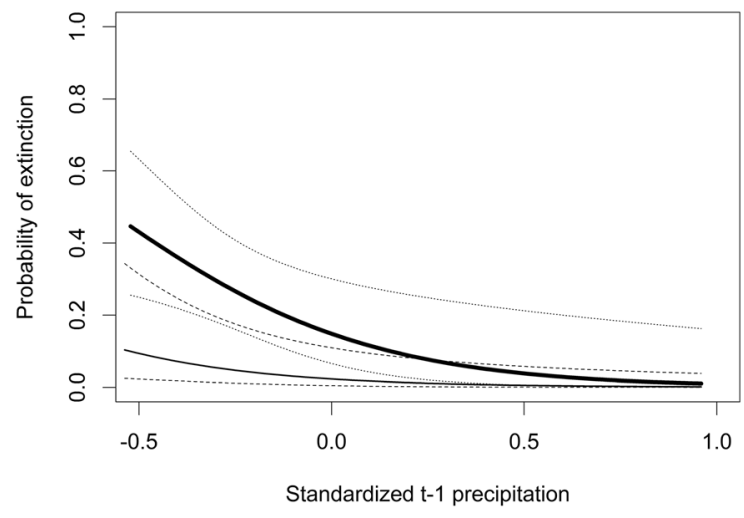

Fig. 4 The relationship between the probability of patch extinction and standardized precipitation. Solid center lines represent best fit from statistical models and dashed outer lines represent the $95 \%$ confidence interval. Thin and thick center lines represent high- and low-quality patches, respectively

sink dynamics of spatially-structured populations, potentially by affecting the spatial variation of trophic processes influencing patch conditions and consequently, caterpillar survival.

Source-sink metapopulations are characterized by persistent populations in good habitat ('sources') coupled to extinction prone populations in poor habitat ('sinks') by one-way migration (Harrison 1991). For example, the checkered white butterfly continually occupies riparian habitat where it can overwinter successfully. Peripheral patches become occupied in the spring but only persist for a few generations until the onset of winter (Shapiro 1979). In this example, habitat quality is seasonally dependent; non-riparian habitat is only a sink in the winter. Like temporal dependence, temporary unfavorable conditions such as those associated with extreme weather events can cause a traditional metapopulation to temporarily exhibit source-sink dynamics. Rare freezes can rapidly degrade habitat and cause mass extinction events except in refuge habitat (Boughton 1999). Flooding events can inundate generally high-quality habitat; populations beyond the flood reaches act as sources to repopulate lower-lying habitat during nonflooding periods (Johnson 2004). We found that interannual variation in precipitation strongly influenced the observed dynamics of A. virginalis. During favorable seasons following wet winters, all patches were occupied and contained more caterpillars than on average, but during unfavorable conditions following droughts, low-quality patches became extinction prone and a higher proportion were unoccupied or had lower caterpillar abundances.

Local versus regional factors

Local patch quality had stronger effects than connectivity on caterpillar abundance and extinction-colonization dynamics. Unlike most studies that use density to determine patch quality, we determined quality through manipulative experiments investigating demography in different habitat patches as suggested by Diffendorfer (1998). Strong bottom-up (unpublished manuscript) and weak top-down forces (predominatry predation by ants; Karban et al. 2013, 2017) conferred a survival advantage to early instar caterpillars in host plant patches occurring within marsh habitat (high-quality) over those in coastal prairie habitat (low-quality). Finding spatial variation of trophic forces is common for ecological studies conducted at the landscape scale (Gripenberg et al. 2007). Accordingly, plant abundance or quality are often used as proxies of patch quality (Mortelliti et al. 2010). It is less common to use predator density or predation intensity as indicators of patch quality. Considering that predators can cause local extinctions (Weisser 2000; van Nouhuys and Hanski 2002), determining patch quality through bottom-up studies alone (i.e., laboratory feeding assays or in situ caging experiments, where predators are excluded) could lead to erroneous conclusions. Moreover, because predators can affect colonization decisions, incomplete understanding of top-down influences could obscure the relative importance of local and regional processes (Shurin 2001; Kneitel and Miller 2003; Grainger et al. 2017; Resetarits et al. 2018).

We found a positive but non-significant relationship between connectivity and caterpillar abundance and patch occupancy. There are two potential explanations for this weak effect. First, connectivity may be less important in this system. In metapopulation studies that included patch quality (Thomas et al. 2001), and those solely concerned with patch geometry (Thomas et al. 1992), connectivity often had little predictive power. Second, connectivity may be important but at a larger spatial scale than considered here (Jackson and Fahrig 2015). However, we did find some evidence that connectivity had a stronger effect on occupancy for low-quality patches compared to high-quality patches (Table 2; Fig. 2). If conditions 
are sufficiently poor because strong predation by ants lowers caterpillar survival, then it is likely that only those poor-quality patches which are highly connected and receive a high level of oviposition will remain occupied.

\section{Precipitation}

We found that precipitation from the previous hydrological year was a good predictor of $A$. virginalis dynamics. Relatively few studies have explicitly quantified the effects of weather on metapopulation dynamics (but see Pardikes et al. 2015; Tack et al. 2015; Kahilainen et al. 2018). One explanation of this paucity is that early studies pooled occupancy data over multiple years to account for stochastic environmental fluctuations (Hanski et al. 1996; Moilanen 1999). The few studies that have modeled the effects of precipitation and temperature or indirectly considered weather effects through changes in patch quality (Fleishman et al. 2002) found strong effects on spatiotemporal population dynamics. Pardikes et al. (2015) found that warmer and wetter years were correlated with increased sightings of numerous butterfly taxa across the study region. In another example, using a 21-year Glanville fritillary butterfly census of over 4000 patches, Tack et al. (2015) demonstrated that droughts synchronized populations. This finding was confirmed by Kahilainen et al. (2018), who also ruled out the possibility of predator-driven synchrony. We found the opposite; increased precipitation synchronized the demographic variables across high- and lowquality patches. Synchronous dynamics of local populations are expected to decrease the persistence time of a metapopulation (Harrison and Quinn 1989; Liebhold et al. 2004). Synchrony reduces the potential for rescue effects (Brown and Kodric-Brown 1977), which are the primary mechanisms promoting regional stability. However, in a system characterized by deterministic extinctions brought about by low patch quality, rescue effects are likely less effective.

Climate models predict a more variable climate with increased frequency and severity of extreme weather events (Coumou and Rahmstorf 2012). This prediction is being borne out in California, where summer droughts are becoming more common (Berg et al. 2015). Indeed, several droughts occurred over the duration of this study (Table 1). If our inference that decreased precipitation increased heterogeneity of patch quality is correct, then the benefit of asynchronous dynamics driven by drought conditions would ultimately destabilize the metapopulation: drier years were associated with more extinction events and a decreased proportion of occupied patches that contained fewer caterpillars compared to wetter years. A reduction in the number of suitable patches (i.e., more sinks) and a decreased number of individuals contributing to the following generation will strongly decrease the probability of regional metapopulation persistence. This work suggests that metapopulations that are largely comprised of drought-sensitive populations existing in low-quality habitat patches are at an increased risk of a network-wide collapse under future climate regimes, when multiyear droughts may become more common.

Reductions in patch size or complete loss of patches resulting from climate change can produce obvious effects. The effects of altered abiotic conditions on patch quality are more difficult to detect. Johnson (2004) demonstrated that extreme weather events contributing to flooding created strong sink habitat, but only during periods of inundation. At the scale of the plant, a metanalysis by Huberty and Denno (2004) showed that water stressed plants are of reduced quality, negatively affecting the performance of several insect feeding guilds. Because the field has focused on testing the importance of regional factors on metapopulation dynamics, the interactive effects of weather variability on patch-quality for spatiallystructured populations is relatively understudied.

\section{Conclusions}

We found that patch quality and precipitation had stronger relative effects than connectivity on all demographic variables of a spatially-structured population of an erebid caterpillar that exhibits sourcesink metapopulation dynamics. Our connectivity metric incorporated the natural history of hilltopping species, namely constrained dispersal though mating aggregations at summits. Though less important than quality and precipitation, finding model support for our connectivity metric indicates its potential usefulness for modeling the spatial dynamics of other systems that exhibit hilltopping and analogous vertebrate mating systems such as lek polygyny (Bradbury and Vehrencamp 1977). Detecting a strong influence 
of precipitation on extinction and colonization dynamics, highlights the importance of incorporating climatic variables in patch-based models to better understand how temperature and precipitation will influence spatially-structured populations in an increasingly variable world.

Acknowledgements Open access funding provided by University of Eastern Finland (UEF) including Kuopio University Hospital. We thank Zack Steel for improving the quality of the manuscript and Jennifer Danger Nill for her quantitative assistance. We thank Jackie Sones and Suzanne Olyarnik for facilitating our work at the UC Bodega Marine Reserve. We were supported by NSF-LTREB-0639885 and 157538.

Open Access This article is distributed under the terms of the Creative Commons Attribution 4.0 International License (http:// creativecommons.org/licenses/by/4.0/), which permits unrestricted use, distribution, and reproduction in any medium, provided you give appropriate credit to the original author(s) and the source, provide a link to the Creative Commons license, and indicate if changes were made.

\section{References}

Alcock J (1987) Leks and hilltopping in insects. J Nat Hist 21:319-328

Anzures-Dadda A, Manson RH (2007) Patch-and landscapescale effects on howler monkey distribution and abundance in rainforest fragments. Anim Conserv 10:69-76

Bates D, Mächler M, Bolker B, Walker S (2015) Fitting linear mixed-effects models using lme4. J Stat Softw 67:1-48

Berg N, Hall A, Berg N, Hall A (2015) Increased interannual precipitation extremes over california under climate change. J Clim 28:6324-6334

Bolker BM, Brooks ME, Clark CJ et al (2009) Generalized linear mixed models: a practical guide for ecology and evolution. Trends Ecol Evol 24:127-135

Boughton DA (1999) Empirical evidence for complex sourcesink dynamics with alternative states in a butterfly metapopulation. Ecology 80:2727

Bradbury JW, Vehrencamp SL (1977) Social organization and foraging in emballonurid bats. Behav Ecol Sociobiol $2: 1-17$

Brown JH, Kodric-Brown A (1977) Turnover rates in insular biogeography: effect of immigration on extinction. Ecology 58:445-449

Coumou D, Rahmstorf S (2012) A decade of weather extremes. Nat Clim Chang 2:491

Diffendorfer JE (1998) Testing models of source-sink dynamics and balanced dispersal. Oikos 81(3):417

Fleishman E, Ray C, Sjögren-gulve P, Boggs CL, Murphy DD (2002) Assessing the roles of patch quality, area, and isolation in predicting metapopulation dynamics. Conserv Biol 16:706-716
Fournier DA, Skaug HJ, Ancheta J, Ianelli J, Magnusson A, Maunder MN, Nielsen A, Sibert J (2012) AD Model builder: using automatic differentiation for statistical inference of highly parameterized complex nonlinear models. Optim Method Soft 27(2):233-249

Franzén M, Nilsson SG (2010) Both population size and patch quality affect local extinctions and colonizations. Proc Biol Sci 277:79-85

Gelman A (2008) Scaling regression inputs by dividing by two standard deviations. Stat Med Stat Med 27:2865-2873

Grainger TN, Germain RM, Jones NT, Gilbert B (2017) Predators modify biogeographic constraints on species distributions in an insect metacommunity. Ecology 98:851-860

Gripenberg S, Roslin T, Gripenberg S, Roslin T (2007) Up or down in space? Uniting the bottom-up versus top-down paradigm and spatial ecology. Res Oikos 116:181-188

Grof-Tisza P, Steel Z, Cole EM, Holyoak M, Karban R (2017) Testing predictions of movement behaviour in a hilltopping moth. Anim Behav 133:161-168

Grof-Tisza P, Steel Z, Karban R (2016) The spatial distribution and oviposition preference of the Ranchman's Tiger Moth, Platyprepia virginalis (Lepidoptera: Erebidae). J Lepid Soc 71:16-19

Hall LS, Krausman PR, Morrison ML (1997) The habitat concept and a plea for standard terminology. Wildl Soc Bull 25:173-182

Hanski I (1994) Patch-occupancy dynamics in fragmented landscapes. Trends Ecol Evol 9:131-135

Hanski I (1998) Metapopulation dynamics. Nature 396:41-49

Hanski I, Moilanen A, Pakkala T, Kuussaari M (1996) The quantitative incidence function model and persistence of an endangered butterfly metapopulation 10:578-590

Hanski I, Thomas CD (1994) Metapopulation dynamics and conservation: a spatially explicit model applied to butterflies. Biol Conserv 68:167-180

Harrison S (1991) Local extinction in a metapopulation context: an empirical evaluation. Biol J Linn Soc 42:73-88

Harrison S, Quinn JF (1989) Nordic Society Oikos correlated environments and the persistence of metapopulations. Oikos 56:293-298

Huberty AF, Denno RF (2004) Plant water stress and its consequences for herbivorous insects: a new synthesis. Ecology $85: 1383-1398$

Huey RB, Kingsolver JG (1989) Evolution of thermal sensitivity of ectotherm performance. Trends Ecol Evol 4:131-135

Hunter MD, Price PW (1992) Playing chutes and ladders: heterogeneity and the relative roles of bottom-up and topdown forces in natural communities. Ecology 73:724-732

Jackson HB, Fahrig L (2015) Are ecologists conducting research at the optimal scale? Glob Ecol Biogeogr 24:52-63

Johnson DM (2004) Source-sink dynamics in a temoporally heterogenous environment. Ecology 85:2037-2045

Kahilainen A, van Nouhuys S, Schulz T, Saastamoinen M (2018) Metapopulation dynamics in a changing climate: increasing spatial synchrony in weather conditions drives metapopulation synchrony of a butterfly inhabiting a fragmented landscape. Glob Chang Biol. 5:6-7 
Karban R, Grof-Tisza P, Holyoak M (2017) Wet years have more caterpillars: interacting roles of plant litter and predation by ants. Ecology 98:2370-2378

Karban R, Grof-Tisza P, Maron JL, Holyoak M (2012) The importance of host plant limitation for caterpillars of an arctiid moth (Platyprepia virginalis) varies spatially. Ecology 93:2216-2226

Karban R, Grof-Tisza P, Mcmmunn M, Kharouba H, Huntzinger $M$ (2015) Caterpillars escape predation in habitat and thermal refuges. Ecol Entomol 40:725-731

Karban R, Mata TM, Grof-Tisza P, Crutsinger G, Holyoak M (2013) Non-trophic effects of litter reduce ant predation and determine caterpillar survival and distribution. Oikos 122:1362-1370

Karban R, de Valpine P (2010) Population dynamics of an Arctiid caterpillar-tachinid parasitoid system using statespace models. J Anim Ecol 79:650-661

Kneitel JM, Miller TE (2003) Dispersal rates affect species composition in metacommunities of Sarracenia purpurea inquilines. Am Nat 162:165-171

Liebhold A, Koenig WD, Bjørnstad ON (2004) Spatial synchrony in population dynamics. Annu Rev Ecol Evol Syst 35:467-490

Moilanen A (1999) Patch occupancy models of metapopulation dynamics: efficient parameter estimation using implicit statistical inference. Ecology 80:1031

Moilanen A, Hanski I (1998) Metapopulation dynamics: effects of habitat quality and landscape structure. Ecology 79:2503-2515

Mortelliti A, Amori G, Boitani L (2010) The role of habitat quality in fragmented landscapes: a conceptual overview and prospectus for future research. Oecologia 163:535-547

van Nouhuys S, Hanski I (2002) Colonization rates and distances of a host butterfly and two specific parasitoids in a fragmented landscape. J Anim Ecol 71:639-650

Pachauri RK, Meyer, AL (2014) Climate change 2014: synthesis report. Contribution of working groups I, II and III to the fifth assessment report of the intergovernmental panel on climate change. IPCC

Painter KJ (2014) Multiscale models for movement in oriented environments and their application to hilltopping in butterflies. Theor Ecol 7:53-75

Pardikes NA, Shapiro AM, Dyer LA, Forister ML (2015) Global weather and local butterflies: variable responses to a largescale climate pattern along an elevational gradient. Ecology 96:2891-2901

Pepi A, Grof-Tisza P, Holyoak M, Karban R (2018) As temperature increases, predator attack rate is more important to survival than a smaller window of prey vulnerability. Ecology. https://doi.org/10.1002/ecy.2356

Pe'er G, Saltz D, Münkemüller T, G, Saltz D, Münkemüller T et al (2013) Simple rules for complex landscapes: the case of hilltopping movements and topography. Oikos. https:// doi.org/10.1111/j.1600-0706.2013.00198.x

Pe'er, Saltz D, Thulke H-H, Motro U, G, Saltz D, Thulke H-H, Motro U (2004) Response to topography in a hilltopping butterfly and implications for modelling nonrandom dispersal. Anim Behav 68:825-839
Powell JA, Opler PA (2009) Moths of Western North America. University of California Press, Berkeley

Prugh LR, Hodges KE, Sinclair ARE, Brashares JS (2008) Effect of habitat area and isolation on fragmented animal populations. Proc Natl Acad Sci USA 105:20770-20775

Pulliam HR (1988) Sources, sinks, and population regulation. Am Nat 132(5):652-661

R Development Core Team (2011) R: a language and environment for statistical computing. R Found Stat Comput 1:409

Rabasa SG, Gutiérrez D, Escudero A (2008) Relative importance of host plant patch geometry and habitat quality on the patterns of occupancy, extinction and density of the monophagous butterfly Iolana iolas. Oecologia 156:491-503

Resetarits WJ, Bohenek JR, Breech T, Pintar MR (2018) Predation risk and patch size jointly determine perceived patch quality in ovipositing treefrogs, Hyla chrysoscelis. Ecology. 5:5-6

Robles H, Ciuad C (2012) Influence of habitat quality, population size, patch size, and connectivity on patch-occupancy dynamics of the middle spotted woodpecker. Conserv Biol 26:284-293

Schooley RL, Branch LC (2009) Enhancing the area-isolation paradigm: habitat heterogeneity and metapopulation dynamics of a rare wetland mammal. Ecol Appl 19:1708-1722

Shapiro A (1979) Wheather and the liability of breeding populations of the checkered white butterfly, Pieris protodice. J Res Lepid 17:1-23

Shields O (1967) Hilltopping: an ecological study of summit congregation behavior of butterflies on a southern California hill. J Res Lepid 6:69-178

Shurin JB (2001) Interactive effects of predation and dispersal on zooplankton communities. Ecology 82:3404-3416

Tack AJM, Mononen T, Hanski I (2015) Increasing frequency of low summer precipitation synchronizes dynamics and compromises metapopulation stability in the Glanville fritillary butterfly. Proc Biol Sci 282:20150173

Thomas JA, Bourn NA, Clarke RT, Stewart KE, Simcox DJ, Pearman GS, Kurtis R, Goodger B (2001) The quality and isolation of habitat patches both determine where butterflies persist in fragmented landscapes. Proc Biol Sci 268:1791-1796

Thomas CD, Harrison S (1992) Spatial dynamics of a patchily distributed butterfly species 61:437-446

Thomas CD, Thomas JA, Warren MS (1992) Distributions of occupied and vacant butterfly habitats in fragmented landscapes. Oecologia 92:563-567

Ver Hoef JM, Boveng PL (2007) Quasi-Poisson vs negative binomial regression: how should we odel overdispersed count data? Ecology 88:2766-2772

Weisser WW (2000) Metapopulation dynamics in an aphidparasitoid system. Entomol Exp Appl 97:83-92

Publisher's Note Springer Nature remains neutral with regard to jurisdictional claims in published maps and institutional affiliations. 